\title{
Prosthetic Management of a Posterior Ridge Defect Case with Fixed Removable Type of Hybrid Prosthesis - A Case Report
}

\author{
Mallika S. Shetty¹, Sanath Kumar Shetty², Suhaim Sayyed Karkala³ ${ }^{3}$ Zahid Mohammed ${ }^{4}$, Tushar Milind Wankhede ${ }^{5}$ \\ 1, 2, 3, 4, 5 Department of Prosthodontics and Crown \& Bridge, \\ Yenepoya Dental College, Yenepoya University, Mangalore, Karnataka, India.
}

\section{INTRODUCTION}

The main aim of prosthetic dentistry is restoring the form, function, comfort and appearance of the patient by the placement of a prosthesis replacing the missing teeth and contiguous tissues. ${ }^{1}$ Various prosthetic options for partially edentulous patients include an interim removable partial denture (RPD) to a cast partial denture, a fixed dental prosthesis (FDP), and a more implant-retained prosthesis.

However, FDP and implant-retained prosthesis are not always feasible, particularly in patients with excessive residual ridge resorption and jaw defects due to trauma and / or surgical ablation. In such a situation, a dentist may resort to another option of fixed-RPD prosthesis, to restore the defective hard and soft tissues to achieve natural aesthetics, phonetics, comfort, and better hygiene. This hybrid prosthesis fulfils the objectives of the rehabilitation such as support, stability, and retention characteristics similar to a fixed prosthesis and aesthetics and hygiene maintenance of a removable prosthesis. ${ }^{2,3,4,5}$

Any prosthesis designed or fabricated should be based on the prosthetic principles of support, stability, retention, and preservation of remaining structures. ${ }^{1}$ From the patient's perspective, retention is one of the important factors for its acceptability. These retentive options range from simple bar and clip attachments to more sophisticated spark erosion overdentures.6,7 Spark erosion prosthesis is technique sensitive, bulky, and requires expensive equipment. ${ }^{6,7}$ On the other hand, precision attachments provide better vertical support and stimulation to the underlying tissue through intermittent vertical massage. ${ }^{8}$

Treatment with a hybrid denture is an affordable choice to fulfil the patient's aesthetic demands along with providing a good prognosis for the prosthesis and preservation of the remaining dentition. This article presents two case reports of prosthodontic rehabilitation of a patient with mandibular defects using an attachment-retained fixed-removable hybrid prosthesis.

\section{PRESENTATION OF CASE}

A 23-year-old female patient reported to the Department of Prosthodontics, Yenepoya Dental College with multiple missing teeth in the mandibular right posterior region. History revealed that the patient had undergone surgery for chronic suppurative osteomyelitis present on the lower right posterior region of the jaw 8 months back, which resulted in a large hard and soft tissue deformity. Examination of maxillary arch revealed bilaterally missing $1^{\text {st }}$ premolars and grossly decayed $2^{\text {nd }}$ premolar of the right side (Fig.1). The remaining teeth were intact and in good periodontal condition. Mandibular arch examination revealed missing lower right canine, premolars, first molar and second premolar on the left side. (Fig.2). Grade 1 recession (According to Miller's classification) was seen on the distal aspect of the lower right lateral incisor with a mesially tilted second molar. Radiographic examination revealed $20 \%$ bone loss in relation to lower right lateral incisor without any clinical mobility. Considering the extent of the defect, a prosthesis that would restore the missing teeth, as well as the deficient part of the ridge, was planned.
Corresponding Author:

Dr. Tushar Milind Wankhede,

Department of Prosthodontics and Crown \& Bridge, Yenepoya Dental College, Yenepoya University, University Road, Deralakatte, Mangalore-575018, Karnataka, India.

E-mail: tuushar18@gmail.com

DOI: $10.14260 / j e m d s / 2021 / 648$

How to Cite This Article:

Shetty MS, Shetty SK, Karkala SS, et al. Prosthetic management of a posterior ridge defect case with fixed removable type of hybrid prosthesis - a case report. J Evolution Med Dent Sci 2021;10(36): 3192-3195, DOI:

10.14260/jemds/2021/648

Submission 26-04-2021,

Peer Review 29-07-2021

Acceptance 06-08-2021,

Published 06-09-2021.

Copyright (C) 2021 Mallika S. Shetty et al. This is an open access article distributed under Creative Commons Attribution License [Attribution 4.0 International (CC BY 4.0)] 


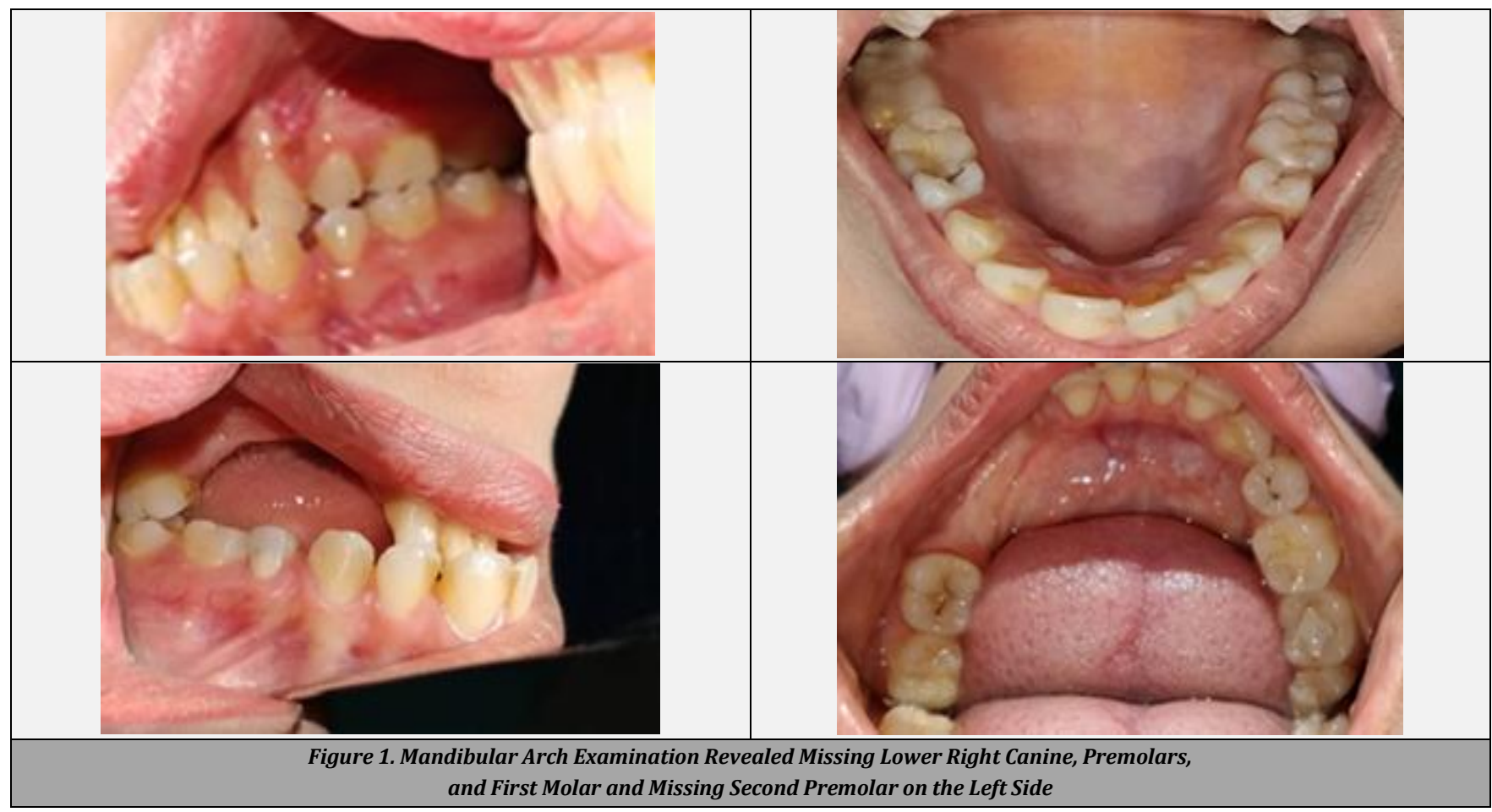

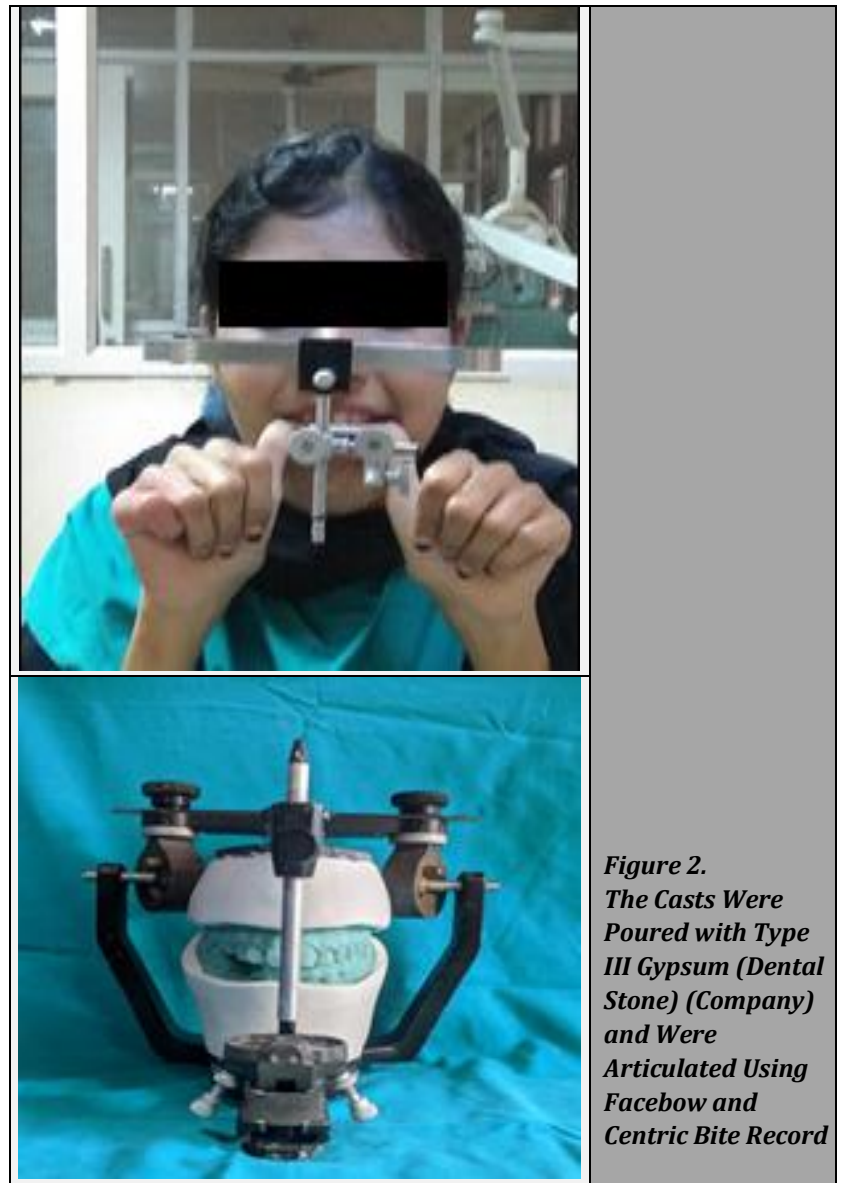

Treatment options included removable cast partial denture, an implant-supported fixed dental prosthesis (FDP). The patient was not willing for a removable prosthesis and did not want a second surgical intervention associated with an implant-supported prosthesis which even accounted for an autologous bone grafting before implant placement. Entirely tooth-supported conventional FDP could not be used in this situation because the pontics would appear elongated and unaesthetic, plus the amount of force exerted during occlusal load would impinge the gingiva, having a negative impact on the residual bone and thus affect the long-term prognosis.

Considering the clinical findings, a fixed-removable type of hybrid prosthesis (Andrew's bridge) using cement retention for the fixed metal fused to ceramic bar framework and Hader bar retention for the RPD was planned for the rehabilitation of this long span Kennedy Class 3 partially edentulous space. The patient was thoroughly explained about the treatment procedures, the outcome and informed consent was obtained.

Diagnostic impressions of the maxillary and mandibular arches were made with irreversible hydrocolloid (Alginate) (Tropicalgin, Zhermack, Italy). The casts were poured with Type III gypsum (Dental stone) (company) and were articulated using facebow and centric bite record. (Fig.3a, Fig. 3b)

On these casts, a diagnostic wax pattern was fabricated of the missing teeth. (Fig.4). A putty index of this pattern was made using the addition silicone putty material (company) to fabricate temporary restoration at a later stage.

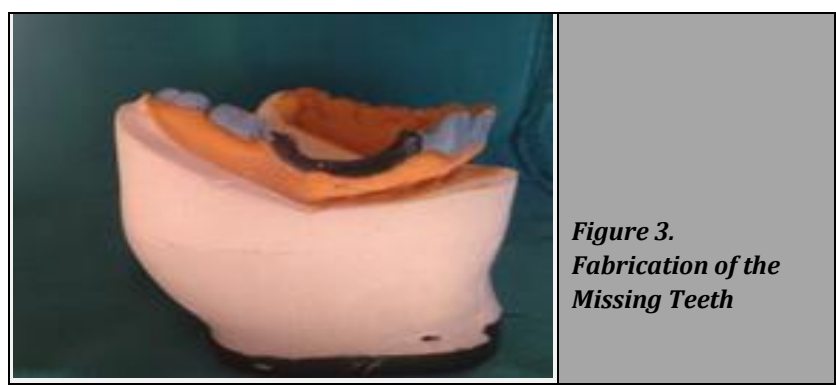

The abutment teeth were prepared to receive porcelain fused to metal restoration with lower right central incisor, lateral incisor and all metal restorations with second and third molar. Gingival retraction was done using Fischer's cord packer (Hu-friedy) and retraction cord (company) having 
Cord no. 00 and 0. Double mix (putty-light body) double step (use of polyethylene sheet as a spacer) impression technique was used to make an impression of the lower arch and poured in die stone (company). Temporization was done using the external surface form and cemented using temporary cement (Temp-Bond, Kerr Corporation, Romulus).

Wax patterns were fabricated for all the prospective abutment teeth using CAD-CAM wax and a wax custom bar running over edentulous deficit ridge was connected to these prepared wax patterns. A Hader bar attachment (Ceka) was attached to the custom bar in the region of the second premolar and first molar. Selection criteria for precision attachment were based on location and length of the edentulous span; function, retention required, and economical constraints of the patient.

Spruing, investing, casting, and finishing and polishing of the nickel-chromium (Ni-Cr) alloy framework were done. Framework try-in was done in the patient's mouth to assess the fit and availability of interarch space. (Fig.5a, Fig.5 b)
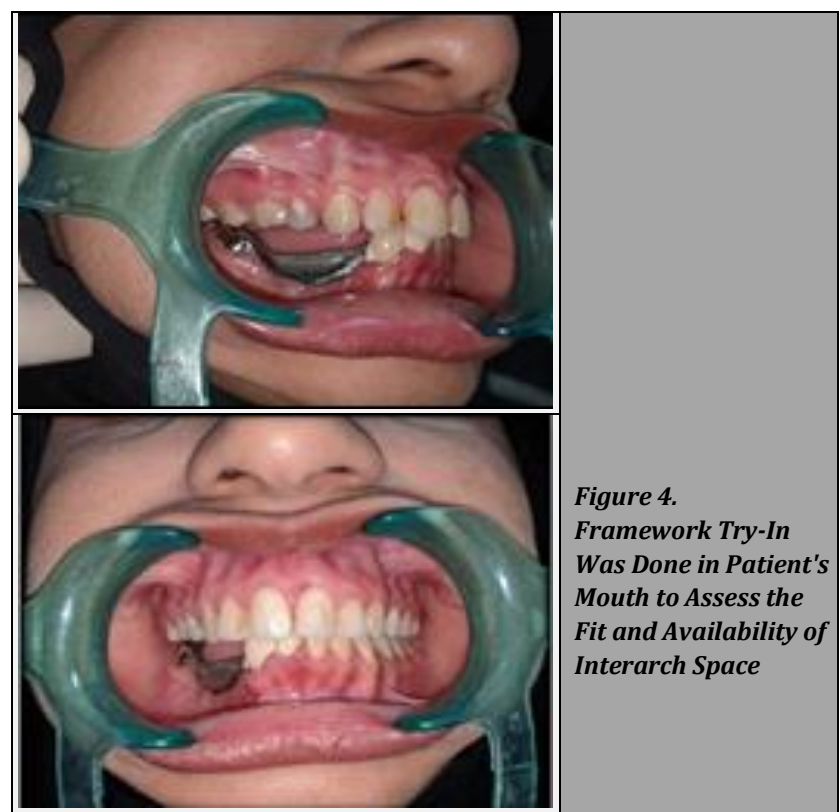

After satisfactory try-in, the ceramic (VITA Zahnfabrik, Germany) layering was done for all the retainers, except for the lower right second and third molar. The bisque trial was done.

A pick-up impression of the mandibular arch using singlestep putty-light body addition silicone was made. The cast was poured using die stone.

Temporary denture base and wax occlusal rim were fabricated covering the edentulous area. The jaw relation was recorded followed by articulation and teeth arrangement. Try in of the partial denture was done and occlusion was evaluated. The cast was invested and flasking was done. After dewaxing, the green fabricating plastic riders were placed at the exact position where the yellow retention rider would come. The metal housings were placed on green riders and the packing and acrylization were done with heat cure acrylic resin (Company).

The acrylized denture was trimmed, finished and polished. The yellow retention riders were placed in the slot of metal housing using the retention clip placement tool. (Fig.6 a, Fig.6 b, Fig.6 c)
The shape of the metal housing provides secure retention of the clips while providing leeway space in the buccolingual direction to allow the clips / riders some flex during insertion or removal of the prosthesis. The denture insertion was done. (Fig.7a, Fig.7 b)
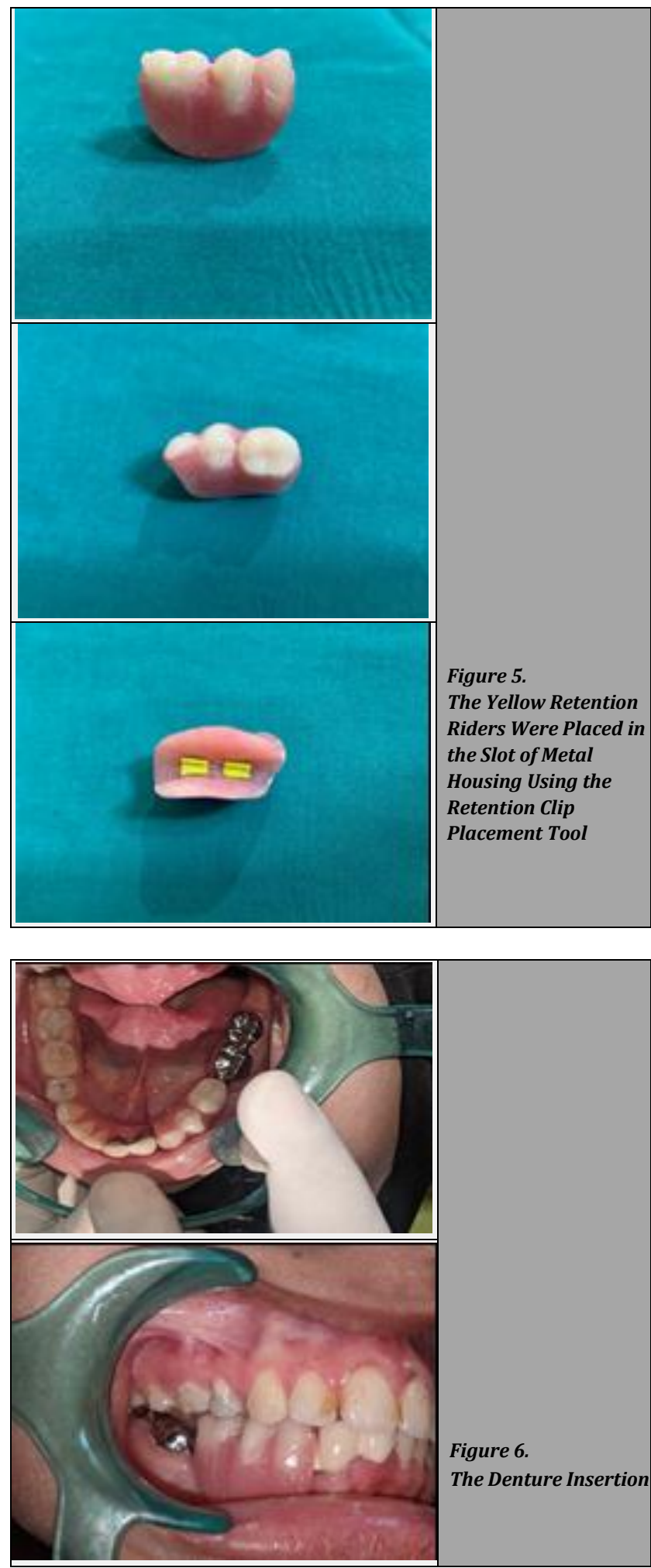

\section{DISCUSSION}

Replacement of missing teeth with prosthesis favours a wide variety of options which includes RPD, FPD, Implant- 
supported FPD, etc. Dr. James Andrews introduced the fixed removable type of hybrid prosthesis where the fixed prosthesis was made of porcelain fused to metal crowns and a premanufactured bar that was incorporated into this framework, while the removable portion was an acrylic partial denture and was retained on to the fixed bar. ${ }^{6}$ This is used mainly when the residual ridge has undergone extensive bone resorption and at the same time the soft tissue loss has taken place resulting in a saucerization bone defect. In such cases, the placement of the pontics of an FPD would compromise aesthetic appearance as it would result in longer crowns and placement of deleterious forces onto the ridge. ${ }^{3}$

Jain et al. ${ }^{4}$ Mueninghoff et al. ${ }^{2}$ and Sabita Ram et al. ${ }^{5}$ have described the rehabilitation of missing anterior teeth with ridge defect using the Andrew's bridge system. Jeyavalan et al. ${ }^{3}$ Patel et al. ${ }^{9}$ Shetty et al. ${ }^{8}$ and Wangoo et al. ${ }^{10}$ have described techniques for oral rehabilitation of missing teeth with ridge defects using an either prefabricated or custommade attachment. An implant is a prosthetic option that was questionable as the available bone height was less and the procedure would have demanded extensive bone grafting. Considering the severity of the defect, FDP was not a suitable treatment option, as it would have resulted in very long pontics, retainers, connectors and the aesthetic and biomechanical outcome of the prosthesis would have been unacceptable. Also, the main difference between a conventional RPD and the Andrew's bridge lies in the distribution of occlusal load. The forces are directed to the underlying tissues, which would cause further resorption of bone in an interim RPD, but, in Andrew's bridge, the forces are transferred partially to the bar that protects the underlying ridge from further resorption.

Considering the prosthetic design of an Andrew's bridge from a functional point of view, a study done by Persic et al. evaluated the effects of various treatment options taking into consideration oral health-related quality of life, aesthetics, mastication and concluded that treatment outcomes were better in the precision attachment-retained RPD than the clasp-retained RPD. ${ }^{11}$

In a case scenario like ours, the patient desired a fixed treatment option which was not possible because of the reasons mentioned before. So, considering the age and financial status, the precision attachment-retained fixedremovable prosthesis was selected over clasp-retained RPD to rehabilitate Kennedy's Class 3 hard and soft-tissue defects with a crown height space of almost $14 \mathrm{~mm}$. A fixedremovable prosthesis is cost-effective and an efficient treatment option for long span partially edentulous cases with a ridge defect. It has retention and stabilizing qualities of a fixed prosthesis and flexibility in teeth arrangement, ease in hygiene maintenance of a removable prosthesis. Along with this, it splints the teeth and provides a biomechanical advantage.

The only disadvantage with this type of prosthesis is that repeated removal and placement will result in wear of the retention clip, thus requiring periodic replacement. Maintenance of oral hygiene and care of the prosthesis is crucial and solely dependent on the patient. The long-term success of the prosthesis is a two-way procedural outcome that depends on the skill of the dentist and applying those skills to provide better treatment to the patient and maintaining the oral hygiene and the prosthesis forms the patient's part.

So, in an ideal clinical scenario, such a fixed-removable type of hybrid prosthesis meets all the demands of function and aesthetic appearance with the added advantage of being kinder to the soft tissues thus preventing further loss.

Financial or other competing interests: None.

Disclosure forms provided by the authors are available with the full text of this article at jemds.com.

\section{REFERENCES}

[1] Cheatham JL, Newland JR, Radentz WH, et al. The 'fixed' removable partial denture: report of case. J Am Dent Assoc 1984;109(1):57-9.

[2] Mueninghoff KA, Johnson MH. Fixed-removable partial denture. J Prosthet Dent 1982;48(6):547-50.

[3] Jeyavalan MI, Narasimman M, Venkatakrishnan CJ, et al. Management of long span partially edentulous maxilla with fixed removable denture prosthesis. Contemp Clin Dent 2012;3(3):314-6.

[4] Jain AR. A prosthetic alternative treatment for severe anterior ridge defect using fixed removable partial denture Andrew's Bar system. World J Dent 2013;4(4):282-5.

[5] Walid MS. Bone anchored Andrew's Bar system a prosthetic alternative. Cairo Dent J 1995;11:11-5.

[6] Weber H, Frank G. Spark erosion procedure: a method for extensive combined fixed and removable prosthodontic care. J Prosthet Dent 1993;69(2):222-7.

[7] Prabhakar BA, Meena A, Cecil W, et al. Precision attachments, applications and limitations. J Evol Med Dent Sci 2012;1(6):1118-26.

[8] Shetty PK, Shetty BY, Hegde M, et al. Rehabilitation of long-span Kennedy class IV partially edentulous patient with a custom attachment-retained prosthesis. J Indian Prosthodont Soc 2016;16(1):83-6.

[9] Patel H, Patel K, Thummer S, et al. Use of precision attachment and cast partial denture for long-span partially edentulous mouth - a case report. Int J Appl Dent Sci 2014;1(1):22-5.

[10] Wangoo A, Kumar S, Phull S, et al. Prosthetic rehabilitation using extra coronal castable precision attachments. Ind J Dent Sci 2014;6:38-40.

[11] Persic S, Kranjcic J, Pavicic DK, et al. Treatment outcomes based on patients' self-reported measures after receiving new clasp or precision attachment-retained removable partial dentures. J Prosthodont 2017;26(2):115-22. 